\title{
Seletividade de herbicidas isolados e em associações para milho RR2/LL ${ }^{\circledR 1}$
}

\author{
Selectivity of herbicide isolated and in associations for $R R 2 / L L^{T M}$ maize
}

André Felipe Moreira Silva ${ }^{2}$; Alfredo Junior Paiola Albrecht ${ }^{3}$; Bruno Flaibam Giovanelli ${ }^{4}$; Giovani Apolari Ghirardello ${ }^{5}$; Vitor Wilson Damião ${ }^{6}$; Leandro Paiola Albrecht ${ }^{7}$; Ricardo Victória Filho $^{8}$

Resumo - O milho com tolerância ao herbicida glyphosate (Roundup Ready ${ }^{\circledR}$ ) (milho $R^{\circledR}{ }^{\circledR}$ ) vem sendo cada vez mais empregado, uma vez que propicia o uso deste herbicida para o controle de plantas daninhas. Assim o objetivo do trabalho foi avaliar a tolerância do híbrido 2B810PW (RR2/LL), submetido à aplicação de glyphosate, glufosinate e atrazine, isolados e associados em pós-emergência (V4). O ensaio foi realizado no campo, na safra 2013/14, e o delineamento adotado foi de blocos casualizados, com quatro repetições. Os tratamentos constituíram-se da aplicação de glyphosate (1080 $\mathrm{g} \mathrm{ha}^{-1}$ de equivalente ácido - e.a.), glufosinate $\left(500 \mathrm{~g} \mathrm{ha}^{-1}\right.$ de ingrediente ativo i.a.), atrazine (2000 g ha ${ }^{-1}$ i.a.), glyphosate + glufosinate, glyphosate + atrazine, glufosinate + atrazine, glyphosate + glufosinate + atrazine, além da testemunha sem aplicação. Foram avaliadas fitointoxicação aos 7, 14, 21 e 28 dias após a aplicação (DAA) e índice SPAD, aos 21 e 28 DAA. Também foram avaliadas variáveis relacionadas ao desempenho agronômico: altura, altura de inserção da espiga, diâmetro do colmo, massa de mil grãos e produtividade. Em geral, as variáveis não foram afetadas pelos tratamentos. O híbrido de milho 2B810 PW apresentou-se tolerante, para a aplicação em pós-emergência (V4) dos herbicidas nas doses utilizadas.

Palavras-chaves: atrazine; culturas tolerantes a herbicidas; glufosinate; glyphosate; Zea mays L.

Abstract - Maize with tolerance to the herbicide glyphosate (Roundup Ready ${ }^{\mathrm{TM}}$ ) (RR2 ${ }^{\mathrm{TM}}$ maize) has been increasingly used, since it favors the use of this herbicide to control weeds. Thus the objective of this study was to evaluate the tolerance of the hybrid 2B810PW (RR2/LL), submitted to the application of isolated and associated of glyphosate, glufosinate and atrazine at postemergency (V4). The assay was carried out in the field, in the harvest 2013/14, and the design adopted was a randomized block with four replications. The treatments consisted of the application

\footnotetext{
${ }^{1}$ Recebido para publicação em 17/11/2016 e aceito em 13/01/2017.

2 Doutorando em Fitotecnia na Universidade de São Paulo - Escola Superior de Agricultura "Luiz de Queiroz", Piracicaba, SP, Brasil. E-mail: <afmoreirasilva@usp.br>.

${ }^{3}$ Professor do Departamento de Ciências Agronômicas da Universidade Federal do Paraná - Setor Palotina, Palotina, PR, Brasil. E-mail: <ajpalbrecht@yahoo.com.br>.

${ }^{4}$ Acadêmico de Engenharia Agronômica na Universidade de São Paulo - Escola Superior de Agricultura "Luiz de Queiroz", Piracicaba, SP, Brasil. E-mail: <bfgiovanelli@yahoo.com.br>.

${ }^{5}$ Acadêmico de Engenharia Agronômica na Universidade de São Paulo - Escola Superior de Agricultura "Luiz de Queiroz", Piracicaba, SP, Brasil. E-mail: <giovani.ghirardello@usp.br>.

${ }^{6}$ Acadêmico de Engenharia Agronômica na Universidade de São Paulo - Escola Superior de Agricultura "Luiz de Queiroz", Piracicaba, SP, Brasil. E-mail: <vitor.damiao@usp.br>.

${ }^{7}$ Professor do Departamento de Ciências Agronômicas da Universidade Federal do Paraná - Setor Palotina, Palotina, PR, Brasil. E-mail: <lpalbrecht@yahoo.com.br〉.

${ }^{8}$ Professor do Departamento de Produção Vegetal da Universidade de São Paulo - Escola Superior de Agricultura "Luiz de Queiroz", Piracicaba, SP, Brasil. E-mail: <rvictori@usp.br>.
} 
of glyphosate (1080 $\mathrm{g} \mathrm{ha}^{-1}$ of acid equivalent - a.e.), glufosinate (500 $\mathrm{g} \mathrm{ha}^{-1}$ of active ingredient a.i.), atrazine (2000 $\mathrm{g} \mathrm{ha}^{-1}$ a.i.), glyphosate + glufosinate, glyphosate + atrazine, glufosinate + atrazine, glyphosate + glufosinate + atrazine, plus the control without application. Crop injury was evaluated at 7, 14, 21 and 28 days after application (DAA) and SPAD index, at 21 and 28 DAA. Were also evaluated variables related to agronomic performance: height, ear height, stem diameter, thousand grain weight and yield. In general, the variables were not affected by treatments. The maize hybrid 2B810 PW presented is tolerant to the application post-emergence (V4) of the herbicides used.

Keywords: atrazine; herbicides-tolerant crops; glufosinate; glyphosate; Zea mays L.

\section{Introdução}

O milho (Zea mays L.), em função de seu potencial produtivo, composição química e valor nutricional, constitui-se um dos mais importantes cereais cultivados e consumidos no mundo (Fancelli e Dourado Neto, 2000). Na safra 2015/16 a área plantada no Brasil foi de 5,38 milhões de hectares, para milho primeira safra, e 10,63 milhões de hectares, para milho segunda safra (CONAB, 2016).

A tecnologia do milho RR2 vem sendo cada vez mais empregada como alternativa para o controle de plantas daninhas que competem com o milho. Esta tecnologia é amplamente empregada em países como Estados Unidos, Canadá, Argentina, África do Sul, Rússia, China entre outros. No Brasil, passou a ser cultivado comercialmente há poucos anos, o que demonstra a necessidade por pesquisas (Albrecht et al., 2014).

O milho RR2 foi desenvolvido devido a problemas que foram observados na primeira geração de milho tolerante ao glyphosate (milho GA21) lançado em 1980 (Albrecht et al., 2014). O desenvolvimento do milho RR2 ocorreu via promotores virais e elementos regulatórios que elevam a expressão da tolerância ao glyphosate na planta, principalmente nos tecidos anteriormente vulneráveis. Possui uma enzima EPSPs diferente da primeira, a homologia desta enzima com a EPSPs selvagem (EPSPs da bactéria Agrobacterium tumefaciens) é de $99,7 \%$. Esta alteração sanou o problema existente com as fitointoxicações (Cajacob, 2007).
Além de híbridos de milho com a tecnologia RR2, têm-se disponíveis no mercado atualmente híbridos com tecnologia de resistência a insetos (milho $\mathrm{Bt}$ ). $\mathrm{O}$ milho $\mathrm{Bt}$ (tecnologias Herculex* ITM $^{\mathrm{TM}}$ Yieldgard $^{\mathrm{TM}}$ ) apresenta também tolerância ao herbicida glufosinate. $\mathrm{O}$ gene que confere tolerância a esse herbicida foi utilizado como marcador de seleção no seu processo de desenvolvimento. Atualmente no Brasil além do milho, soja e algodão também apresentam tolerância ao glufosinate $\left(\right.$ Liberty $\left.^{\circledR}\right)$, estas culturas apresentam a tecnologia Liberty Link ${ }^{\circledR}\left(\mathrm{LL}^{\circledR}\right)$ (Oliveira Júnior, 2011). A tolerância ao glufosinate ocorre devido à enzima phosphinothricin acetyltransferase (PAT) de Streptomyces viridochromogenes (Herouet et al., 2005).

A associação de herbicidas trata-se de uma importante ferramenta no manejo de plantas daninhas de difícil controle. Pesquisa de Gazziero (2015), que entrevistou produtores rurais e profissionais da área, concluiu que para 97\% dos entrevistados a mistura em tanque é uma prática usual. Com a utilização do milho $\mathrm{RR} 2 / \mathrm{LL}^{\circledR}{ }^{\circledR}$, surgem dúvidas relacionadas às associações de glyphosate e glufosinate com outros herbicidas utilizados em milho, uma vez que, algumas associações têm o risco de causar fitointoxicação na cultura ou comprometer a eficácia de controle das plantas daninhas (Albrecht et al., 2014).

Devido à escassez de informações sobre o assunto, o objetivo deste trabalho foi avaliar a tolerância do híbrido 2B810PW (RR2/LL ${ }^{\circledR}$ ), submetido à aplicação em pós-emergência (V4) 
de glyphosate, glufosinate e atrazine, isolados e associados.

\section{Material e Métodos}

O presente trabalho foi conduzido na safra 2013/14, no campo em área experimental pertencente ao Departamento de Produção Vegetal da Universidade de São Paulo - Escola Superior de Agricultura "Luiz de Queiroz", no município de Piracicaba (SP).

A Tabela 1 apresenta a análise química e física do solo da área experimental.

Tabela 1. Resultado da análise química do solo da área experimental, na profundidade de 0 a 20 cm. Piracicaba (SP), 2013/2014.

\begin{tabular}{cccccccccc}
\hline $\mathrm{pH}\left(\mathrm{CaCl}_{2}\right)$ & $\mathrm{Al}$ & $\mathrm{H}+\mathrm{Al}$ & $\mathrm{P}($ resina) & $\mathrm{K}$ & $\mathrm{Ca}$ & $\mathrm{Mg}$ & $\mathrm{SB}$ & $\mathrm{CTC}$ & $\mathrm{V}$ \\
\hline 5,3 & $<1,0$ & 25,0 & 7,0 & 2,6 & 39,0 & 16 & 47,6 & 66,8 & 70 \\
\hline & Argila & & \multicolumn{3}{c}{ Silte } & & & Areia & \\
\hline & & & 6,0 & & \multicolumn{3}{c}{54,0} \\
\hline
\end{tabular}

Unidades: $\mathrm{Al}, \mathrm{H}+\mathrm{Al}, \mathrm{K}, \mathrm{Ca}, \mathrm{Mg}, \mathrm{SB}$ e CTC $\left(\mathrm{mmol}_{\mathrm{c}} \mathrm{dm}^{-3}\right) ; \mathrm{P}$ (resina) $\left(\mathrm{mg} \mathrm{dm}^{-3}\right)$; $\mathrm{V}$, argila, silte, areia (\%).

$\mathrm{Na}$ Figura 1 está apresentada a distribuição de precipitação e temperatura mínima e máxima do ar ao longo do período de condução do experimento no campo (USP/ESALQ).

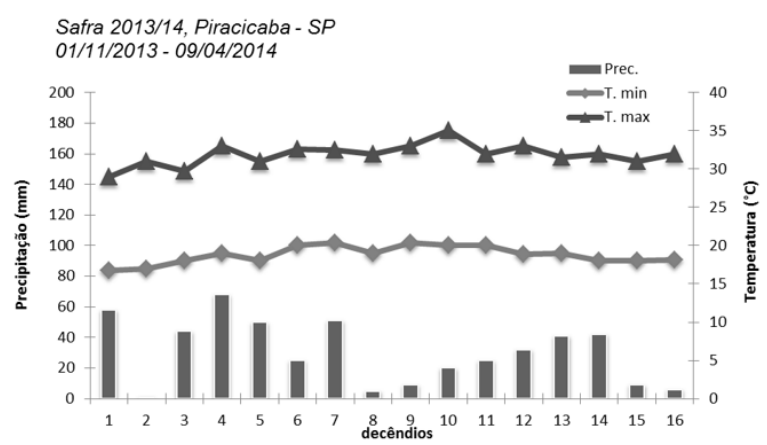

Figura 1. Precipitação, temperatura média mínima e temperatura média máxima para o período referente ao ciclo da cultura do milho. Piracicaba (SP), 2013/2014.

O híbrido simples utilizado foi o 2B810PW, que apresenta resistência a lepidópteros além das tecnologias $\mathrm{RR} 2^{\circledR} \mathrm{e} \mathrm{LL}^{\circledR}$, em sistema de semeadura direta realizada dia 02/12/2013. O emprego das práticas de adubação, instalação da cultura e manejo fitossanitários foram realizados de acordo com as recomendações da EMBRAPA (2012), e todas as parcelas foram mantidas livres de plantas daninhas por meio de capinas.
O delineamento experimental utilizado foi de blocos casualizados, com quatro repetições. As unidades experimentais foram constituídas por parcelas de 5 metros de comprimento e quatro linhas de milho, espaçadas a $0,8 \mathrm{~m}$ entre elas, e a área útil foi composta pelas duas linhas centrais descartando-se meio metro em cada extremidade da parcela.

Foram utilizados os herbicidas glyphosate (Roundup Ready, $480 \mathrm{~L}^{-1}$ g e.a., CS, Monsanto), glufosinate (Liberty, $200 \mathrm{~L}^{-1} \mathrm{~g}$ i.a., CS, Bayer) e atrazine (Proof, $500 \mathrm{~L}^{-1} \mathrm{~g}$ i.a., SC, Syngenta), nas doses de $1080 \mathrm{~g} \mathrm{ha}^{-1}$ e.a., $500 \mathrm{e}$ $2000 \mathrm{~g} \mathrm{ha}^{-1}$ i.a., respectivamente. Os tratamentos foram constituídos pela aplicação isolada de cada um dos herbicidas; pela aplicação das associações de glyphosate + glufosinate, glyphosate + atrazine e glufosinate + atrazine; pela aplicação da associação dos três herbicidas; e pela testemunha sem aplicação, totalizando assim 8 tratamentos.

A aplicação dos tratamentos ocorreu no dia 21 de dezembro de 2013, quando o milho se encontrava no estádio V4, via pulverizador costal pressurizado a $\mathrm{CO}_{2}$, equipado com barra com 6 pontas tipo leque, da série Teejet tipo XR 110.02, a uma pressão constante de 2 Bar, propiciando um volume de calda de $200 \mathrm{~L} \mathrm{ha}^{-1}$, e velocidade de $1 \mathrm{~m} \mathrm{~s}^{-1}$, sendo que as pontas foram posicionadas a uma altura de $50 \mathrm{~cm}$ do 
alvo. As condições climáticas durante a aplicação foram: umidade relativa do ar de 67\%; velocidade do vento de $2 \mathrm{~km} \mathrm{~h}^{-1}$ e temperatura (T) de $25,1{ }^{\circ} \mathrm{C}$.

A porcentagem de fitointoxicação foi avaliada por meio de notas visuais (0 para ausência de injúrias, até $100 \%$ para morte das plantas), considerando-se neste caso sintomas significativamente visíveis nas plantas, de acordo com seu desenvolvimento (SBCPD, 1995). Esta avaliação foi realizada aos 7, 14, 21, e 28 dias após aplicação (DAA). Ressalta-se que para esses dados foi necessário utilizar a opção de transformação $(X+1)^{\wedge} 0,5$.

Também foi realizada avaliação do índice SPAD (Soil Plant Analysis Development), para a qual foi utilizado o medidor portátil SPAD-502, da empresa Minolta. Este instrumento avalia, quantitativamente, a intensidade do verde da folha, via medição das transmissões de luz a 650 e $940 \mathrm{~nm}$. Com estes dois valores, o equipamento calcula um número ou índice SPAD que normalmente é correlacionado com o teor de clorofila da folha (Markwell et al., 1995). Esta avaliação ocorreu aos 21 e 28 DAA e a aferição do índice foi realizada na porção média da terceira folha totalmente expandida, sendo feita em 10 plantas, escolhidas ao acaso na área útil das parcelas.

Ainda foi realizada avaliação de variáveis relacionadas ao desempenho agronômico (diâmetro de colmo, altura da inserção da espiga, altura total das plantas, produtividade, e massa de mil grãos). Estes dados foram coletados após o ponto de maturidade fisiológica da cultura (R6), quando os grãos se encontravam com umidade no ponto de colheita, e as coletas ocorreram dentro da área útil das parcelas.

Para a determinação destas variáveis foram também avaliadas 10 plantas, escolhidas ao acaso na área útil das parcelas. Para as avaliações de altura foi utilizada régua milimetrada de madeira, com os resultados expressos em centímetros. Para a avaliação de diâmetro do colmo foi utilizado paquímetro, com os resultados expressos em milímetros, medição realizada a $20 \mathrm{~cm}$ de altura em relação ao nível do solo.

Para estimar a produtividade, as espigas da área útil das parcelas foram colhidas manualmente, debulhadas em trilhadora para experimentos, limpas com o auxílio de peneiras e acondicionadas em sacos de papel. Os grãos produzidos em cada parcela tiveram sua massa aferida e a umidade corrigida para $13 \%$, a partir destes dados foi calculada a produtividade. Para a massa de mil grãos foi aferida a massa de duas sub-amostras por parcela e a umidade corrigida para $13 \%$.

Os dados obtidos foram submetidos à análise de variância e teste $\mathrm{F}$, e as médias dos tratamentos foram comparadas pelo teste de Tukey $(\mathrm{p}<0,05)$, conforme Pimentel-Gomes e Garcia (2002).

\section{Resultados e Discussão}

Sintomas de fitointoxicação foram observados, entretanto valores não ultrapassaram $4,50 \%$, resultado este observado aos 7 DAA. Ressalta-se que aos 14, 21 e 28 DAA não foram observadas quaisquer injúrias nas plantas de milho (Tabela 2). De maneira semelhante, a aplicação dos herbicidas em pósemergência (V4) não interferiram na variávelresposta índice SPAD (Tabela 2), bem como nas variáveis relacionadas ao desempenho agronômico (Tabela 3).

Vários pesquisadores verificaram que a aplicação em pós-emergência de glyphosate, em doses entre 840 e $2880 \mathrm{~g} \mathrm{ha}^{-1}$ e.a., não causou sintomas de fitointoxicação em plantas de milho RR $^{\circledR}$ (Nurse et al., 2008; Burke et al., 2008; Vieira Júnior et al., 2015; Albrecht et al., 2016). Soltani et al. (2010) observaram sintomas de fitointoxicação, entretanto inferiores a $2 \%$, para dose de $900 \mathrm{~g} \mathrm{ha}^{-1}$ e.a. Vieira Júnior et al. (2015) e Osório et al. (2015) também verificaram que aplicação de glyphosate não alterou a altura, altura de inserção de espiga, diâmetro do colmo e produtividade das plantas de milho. 
Tabela 2. Fitointoxicação (\%) aos 7, 14, 21 e 28 DAA e índice SPAD aos 21 e 28 DAA, para aplicação de herbicidas isolados ou associados, em pós-emergência (V4) de milho RR2/LL ${ }^{\circledR}$. Piracicaba (SP), 2013/2014.

\begin{tabular}{|c|c|c|c|c|c|c|c|}
\hline \multirow{2}{*}{ Tratamentos } & \multicolumn{5}{|c|}{ Fitointoxicação } & \multicolumn{2}{|c|}{ Índice SPAD } \\
\hline & $7 *$ & & $14^{\mathrm{NS}}$ & $21^{\mathrm{NS}}$ & $28^{\mathrm{NS}}$ & $21^{\mathrm{NS}}$ & $28^{\mathrm{NS}}$ \\
\hline 1. Testemunha & 0,00 & $\bar{a}$ & 0,00 & 0,00 & 0,00 & 41,45 & 44,48 \\
\hline 2. GLY & 2,75 & $\mathrm{~b}$ & 1,50 & 0,75 & 0,00 & 43,30 & 43,28 \\
\hline 3. GLU & 4,00 & $\mathrm{~b}$ & 4,00 & 0,00 & 0,00 & 44,98 & 39,63 \\
\hline 4. ATR & 3,50 & $\mathrm{~b}$ & 3,00 & 0,00 & 0,00 & 41,45 & 43,20 \\
\hline 5. GLY + GLU & 3,00 & $\mathrm{~b}$ & 4,00 & 0,00 & 0,00 & 44,80 & 39,43 \\
\hline 6. GLY + ATR & 4,50 & $\mathrm{~b}$ & 1,50 & 0,00 & 0,00 & 42,03 & 41,88 \\
\hline 7. GLU + ATR & 2,25 & $a b$ & 2,00 & 0,00 & 0,00 & 42,75 & 42,15 \\
\hline 8. GLY + GLU + ATR & 3,50 & $\mathrm{~b}$ & 3,75 & 0,00 & 0,00 & 43,53 & 43,25 \\
\hline Média & 2,75 & & 2,47 & 0,09 & 0,00 & 43,15 & 42,26 \\
\hline DMS & 3,08 & & 4,31 & 1,26 & 0,00 & 6,77 & 7,37 \\
\hline C.V. $(\%)$ & 16,46 & & 29,50 & 17,14 & 0,00 & 6,62 & 7,37 \\
\hline
\end{tabular}

GLY = glyphosate (1080 $\mathrm{g} \mathrm{ha}^{-1}$ e.a.); GLU = glufosinate (500 $\mathrm{g} \mathrm{ha}^{-1}$ i.a.); ATR = atrazine (2000 $\mathrm{g} \mathrm{ha}^{-1}$ i.a.). * Médias seguidas pela mesma letra na coluna não diferem entre si a $5 \%$ de probabilidade, pelo teste Tukey. ${ }^{\text {NS }}$ Médias não diferem entre si a $5 \%$ de probabilidade, pelo teste Tukey.

Tabela 3. Variáveis relacionadas ao desempenho agronômico, para aplicação de herbicidas isolados ou associados, em pós-emergência (V4) de milho RR2/LL ${ }^{\circledR}$. Piracicaba (SP), 2013/2014.

\begin{tabular}{lccccc}
\hline \multicolumn{1}{c}{ Tratamentos } & $\mathrm{AT}^{\mathrm{NS}}$ & $\mathrm{AIE}^{\mathrm{NS}}$ & $\mathrm{DC}^{\mathrm{NS}}$ & $\mathrm{MG}^{\mathrm{NS}}$ & $\mathrm{PRO}^{\mathrm{NS}}$ \\
\hline 1. Testemunha & 206,25 & 103,00 & 20,10 & 220,75 & 9201,87 \\
2. GLY & 211,50 & 103,50 & 20,87 & 218,56 & 9511,24 \\
3. GLU & 201,75 & 99,00 & 19,52 & 224,83 & 8810,33 \\
4. ATR & 206,25 & 98,50 & 19,74 & 207,50 & 8123,56 \\
5. GLY + GLU & 212,00 & 102,50 & 19,81 & 225,75 & 8972,63 \\
6. GLY + ATR & 210,75 & 103,00 & 20,10 & 225,79 & 9206,52 \\
7. GLU + ATR & 206,75 & 101,25 & 19,98 & 209,64 & 8748,28 \\
8. GLY + GLU + ATR & 200,50 & 99,75 & 20,19 & 220,66 & 8523,33 \\
\hline Média & 206,97 & 101,33 & 20,03 & 219,18 & 8887,22 \\
DMS & 17,95 & 11,39 & 2,31 & 31,58 & 1915,14 \\
C.V. $(\%)$ & 3,66 & 4,74 & 4,84 & 6,07 & 9,08 \\
\hline GLY
\end{tabular}

GLY = glyphosate (1080 $\mathrm{g} \mathrm{ha}^{-1}$ e.a. $)$; GLU = glufosinate (500 $\mathrm{g} \mathrm{ha}^{-1}$ i.a. $)$; ATR = atrazine (2000 $\mathrm{g} \mathrm{ha}^{-1}$ i.a. $)$; AT = altura total $(\mathrm{cm}) ;$ AIE = altura de inserção da espiga $(\mathrm{cm}) ; \mathrm{DC}=$ diâmetro do colmo $(\mathrm{mm}) ; \mathrm{MG}=$ massa de 1000 grãos $(\mathrm{g})$; $\mathrm{PRO}=$ produtividade $\left(\mathrm{kg} \mathrm{ha}^{-1}\right) .{ }^{\text {NS }}$ Médias não diferem entre si a 5\% de probabilidade, pelo teste Tukey.

A aplicação em pós-emergência de glufosinate não causou sintomas de fitointoxicação em plantas de milho $\mathrm{LL}^{\circledR}$ na dose $470 \mathrm{~g} \mathrm{ha}^{-1}$ i.a. (Burke et al., 2008). Armel et al. (2008) observaram sintomas de fitointoxicação de até 6 e $23 \%$ quando a aplicação de glufosinate + mesotrione $(300+70$ $\mathrm{g} \mathrm{ha}^{-1}$ i.a.) foi realizada em pós-inicial e póstardia (aproximadamente 20 e 40 dias após o plantio) entretanto não foram verificadas reduções em produtividade das plantas de milho. Assim como esses, outros trabalhos: Ritter e Menbere (2001), Shrestha et al. (2001),
Tharp e Kells (2001) também demonstram a eficácia e seletividade do glufosinate na cultura do milho.

A aplicação em pós-emergência de glyphosate $\left(960 \mathrm{~g} \mathrm{ha}^{-1}\right.$ e.a.) + atrazine (1000 g ha $^{-1}$ i.a.) não alterou a massa de 400 grãos e produtividade (Correia e Santos, 2013), e também não reduziu altura, altura de inserção da espiga e ICV (índice de cor verde), na dose de $1440 \mathrm{~g} \mathrm{ha}^{-1}$ e.a. $+1500 \mathrm{~g} \mathrm{ha}^{-1}$ i.a. (Osório et al., 2015). Soltani et al. (2010) observaram sintomas de fitointoxicação inferiores a $2 \%$ para 
glyphosate $\left(900 \mathrm{~g} \mathrm{ha}^{-1}\right.$ e.a. $)+$ atrazine $\left(700 \mathrm{~g} \mathrm{ha}^{-}\right.$ ${ }^{1}$ i.a.) sem reduções em produtividade.

Assim como Santos et al. (2015) e Singh et al. (2015) não observaram redução em produtividade de milho para aplicação em pósemergência de atrazine, nas doses 1500 e 1000 $\mathrm{g} \mathrm{ha}^{-1}$ i.a., respectivamente. Gemelli et al. (2013) também não verificaram reduções em produtividade de milho $\mathrm{RR} 2 / \mathrm{LL}^{\circledR}$ para aplicação em pós-emergência de glyphosate (960 $\mathrm{g} \mathrm{ha}^{-1}$ e.a.) + atrazine (1500 $\mathrm{g} \mathrm{ha}^{-1}$ i.a.) e glufosinate $\left(600 \mathrm{~g} \mathrm{ha}^{-1}\right.$ e.a. $)+$ atrazine $(1500 \mathrm{~g}$ ha $^{-1}$ i.a.).

A associação e rotação de herbicidas tratam-se de importantes ferramentas no manejo de plantas daninhas e também na prevenção de seleção de biótipos resistentes a herbicidas (Green, 2007; Riar et al. 2013). Nesse contexto a tecnologia $\mathrm{LL}^{\circledR}$ ganha destaque, devido à possibilidade do uso do herbicida glufosinate. Entretanto, poucos trabalhos são encontrados na literatura, conduzidos nas condições edafoclimáticas brasileiras. Resultados obtidos no presente trabalho são de grande importância no posicionamento do glufosinate, isolado ou associado a outros herbicidas utilizados na cultura do milho.

\section{Conclusão}

O híbrido de milho 2B810 PW $\left(\mathrm{RR} 2 / \mathrm{LL}^{\circledR}\right)$ é tolerante à aplicação em pósemergência (V4), de glyphosate, glufosinate e atrazine, isolados e associados.

\section{Referências}

Albrecht, A.J.P.; Albrecht, L.P.; Barroso, A.A.M.; Victoria Filho, R. O milho RR2 e o glyphosate: Uma revisão. Revista Brasileira de Herbicidas, v.13, n.1, p.58-67, 2014.

Albrecht, A.J.P.; Silva, A.F.M.; Albrecht, L.P.; Giovanelli, B.F.; Ghirardello, G.A.; Aiello, L.H.F. et al. Aplicação de diferentes manejos, formulações e doses de glyphosate, sobre o desenvolvimento do milho RR2. Journal of Agronomic Sciences, v.5, n.2, p.114-124, 2016.
Armel, G.R.; Richardson, R.J.; Wilson, H.P.; Hines, T.E. Mesotrione and glufosinate in glufosinate-resistant corn. Weed Technology, v.22, n.4, p.591-596, 2008.

Burke, I.C.; Thomas, W.E.; Allen, J.R.; Collins, J.; Wilcut, J.W. A comparison of weed control in herbicide-resistant, herbicide-tolerant, and conventional corn. Weed Technology, v.22, n.4, p.571-579, 2008.

Cajacob, C.A. Genetically modified herbicide resistant crops. In: Kramer, W.E; Schirmer, W. (Ed.). Modern Crop Protection Compounds. Weinheim: Wiley-vch, 2007. p.283-316.

Companhia Nacional do Abasteciemento CONAB. Acompanhamento da safra brasileira: grãos: safra 2015/2016, nono levantamento, junho de 2016. Brasília: CONAB, 2016. 174p.

Correia, N.M.; Santos, E.A. Foliar levels of macro and micronutrients in glyphosate-tolerant corn submitted to herbicides. Semina-Ciencias Agrarias, v.34, p.3165-3171, 2013.

Empresa Brasileira de Pesquisa Agropecuária EMBRAPA. Sistemas de Produção: Cultivo do Milho. 2012. Disponível em: <http://www.cnpms.embrapa.br/publicacoes/mi 1ho_8_ed/index.ht>. Acesso em: 13 abr. 2016.

Fancelli, A.L.; Dourado Neto, D. Ecofisiologia e fenologia. In: Fancelli, A.L.; Dourado Neto, D. (Ed.). Produção de milho. Guaíba: Agropecuária, 2000. p.21-54.

Gazziero, D.L.P. Misturas de agrotóxicos em tanque nas propriedades agrícolas do Brasil. Planta Daninha, v.33, n.1, p.83-92, 2015.

Gemelli, A.; Oliveira Jr., R.S.; Constantin, J.; Braz, G.B.P.; Jumes, T.M.C.; Gheno, E.A. et al. Estratégias para o controle de capim-amargoso (Digitaria insularis) resistente ao glyphosate na cultura milho safrinha. Revista Brasileira de Herbicidas, v.12, n.2, p.162-170, 2013.

Green, J.M. Review of glyphosate and ALSinhibiting herbicide crop resistance and resistant 
weed management. Weed Technology, v.21, n.2, p.547-558, 2007.

Herouet, C.; Esdaile, D.J.; Mallyon, B.A.; De Bruyne, E.; Schulz, A.; Currier, T. et al. Safety evaluation of the phosphinothricin acetyltransferase proteins encoded by the pat and bar sequences that confer tolerance to glufosinate-ammonium herbicide in transgenic plants. Regulatory Toxicology and Pharmacology, v.41, n.2, p.134-149, 2005.

Markwell, J.; Osterman, J.C.; Mitchell, J.L. Calibration of the Minolta SPAD-502 leaf chlorophyll meter. Photosynthesis Research, v.46, n.3, p.467-472, 1995.

Nurse, R.E. Hamill, A.S.; Kells, J.J.; Sikkema, P.H. Annual weed control may be improved when AMS is added to below-label glyphosate doses in glyphosate-tolerant maize (Zea mays L.). Crop Protection, v.27, n.3-5, p.452-458, 2008.

Oliveira Jr., R.S. Mecanismos de Ação dos Herbicidas. In: Oliveira Jr., R.S.; Constantin, J.; Inoue, M.H. (Ed.). Biologia e Manejo de Plantas Daninhas. Curitiba: Ominipax, 2011. p.141-192.

Osório, C.W.; Bardiviesso, D.M.; Souza, E.I.S.; Leite, R.C.; Leal, A.J.F.; Souza, H.M. Milho RR submetido a diferentes manejos de herbicidas e adubação foliar. Nativa, v.3, n.2, p.78-82, 2015.

Pimentel-Gomes, F.; Garcia, C.H. Estatística aplicada a experimentos agronômicos e florestais: exposição com exemplos e orientações para uso de aplicativos. Piracicaba: FEALQ, 2002. 309p.

Riar, D.S.; Norsworthy, J.K.; Steckel, L.E.; Stephenson, D.O.; Eubank, T.W.; Bond, J. et al. Adoption of best management practices for herbicide-resistant weeds in midsouthern United States cotton, rice, and soybean. Weed Technology, v.27, n.4, p.788-797, 2013.

Ritter, R.L.; Menbere, H. Weed management systems utilizing glufosinate-resistant corn ( $\mathrm{Zea}$ mays) and soybean (Glycine max). Weed Technology, v.15, n.1, p. 89-94, 2001.

Santos, M.V.; Silva, D.V., Fonseca, D.M.D.; Reis, M.R.D.; Ferreira, L.R.; Oliveira Neto, S.N.D. et al. Productive components of maize under different weed management systems and planting arrangements in agrosilvopasture system. Ciencia Rural, v.45, n.9, p.1545-1550, 2015.

Shrestha, A.; Rajcan, I.; Chandler, K.; Swanton, C.J. An integrated weed management strategy for glufosinate-resistant corn (Zea mays). Weed Technology, v.15, n.3, p.517-522, 2001.

Singh, A.K.; Parihar, C.M.; Jat, S.L.; Singh, B.; Sharma, S. Weed management strategies in maize (Zea mays): Effect on weed dynamics, productivity and economics of the maize-wheat (Triticum aestivum) cropping system in Indogangetic plains. Indian Journal of Agricultural Sciences, v.85, n.1, p.87-92, 2015.

Sociedade Brasileira da Ciência das Plantas Daninhas - SBCPD. Procedimentos para instalação, avaliação e análise de experimentos com herbicidas. Londrina: SBCPD, 1995. 42p.

Soltani, N.; Van Eerd, L.L.; Vyn, R.J.; Shropshire, C.; Sikkema, P.H. Weed control, environmental impact and profitability with glyphosate tank mixes in glyphosate-tolerant corn. Canadian Journal of Plant Science, v.90, n.1, p.125-132, 2010.

Tharp, B.E.; Kells, J.J. Effect of glufosinateresistant corn (Zea mays) population and row spacing on light interception, corn yield, and common lambsquarters (Chenopodium album) Growth. Weed Technology, v.15, n.3, p.413418, 2001.

Vieira Júnior, N.S.; Jakelaitis, A.; Cardoso, I.S.; Rezende, P.N.; Moraes, N.C.; Araújo, V.T. et al. Associação de herbicidas aplicados em pósemergência na cultura do milho. Global Science and Technology, v.8, n.1, p.1-8, 2015. 